


\title{
Development and Verification of an Integrated Physicochemical and Geochemical Modelling Framework for Performance Assessment of Cement-Based Materials
}

\author{
Yogarajah Elakneswaran ${ }^{1}$ and Tetsuya Ishida ${ }^{2}$
}

Received 28 June 2013, accepted 8 April 2014

doi:10.3151/jact.12.111

\begin{abstract}
In this study, a multi-scale model called DuCOM (Durability COncrete Model), which is developed by the Concrete Laboratory at the University of Tokyo, is extended by coupling the geochemical code PHREEQC. The coupled numerical framework can address physicochemical and geochemical processes such as the hydration of cement particles, pore structure formation, multispecies transport, activity effect, thermodynamic reaction between aqueous solution and solids, etc. in cementitious materials, and therefore, it can potentially be used to assess the long-term durability of concrete structures. The model prediction for the composition of cement hydrates, pore solution chemistry, calcium profiles for the cement paste exposed in pure water, and calcium and sulphur profiles for the cement paste immersed in the sodium sulphate solution are qualitatively and quantitatively compared with experimental results obtained from literature. Finally, the importance of the strong coupling among various processes and mechanisms in the DuCOM-PHREEQC system is discussed.
\end{abstract}

\section{Introduction}

The deterioration of cementitious materials in concrete structures is causing concern worldwide today. Ensuring the adequate durability of concrete structures in aggressive environments is a primary issue for engineers. The ingress of detrimental ions and consequent chemical reactions represent the greatest threat to the durability of cementitious materials. The long-term performance of the materials in aggressive aqueous environments needs to be evaluated by both experimental techniques and modelling approaches.

Several numerical models have been developed in the past to predict the long-term performance of cementitious materials in aggressive environments (Elakneswaran et al. 2010; Hosokawa et al. 2011; Ishida et al. 2009; Maekawa et al. 2009; Marchand et al. 2002). These models are improving with understanding the deterioration phenomena through different aspects of the mechanisms and coupling between them. Reactive transport models are an essential tool to evaluate the performance of cementitious materials because the degradation has to be predicted precisely with time at each point of the materials. In recent years, many reports have been published on multispecies transport and coupling of the transport model with chemical reactions (Elakneswaran et al. 2010; Hosokawa et al. 2011; Kari et al. 2013; Marchand et al. 2002). The STADIUM

\footnotetext{
${ }^{1}$ Project Research Associate, Department of Civil Engineering, University of Tokyo, Japan.

E-mail: laknesh@concrete.t.u-tokyo.ac.jp

${ }^{2}$ Professor, Department of Civil Engineering, University of Tokyo, Japan.
}

model developed by Marchand et al. (2002) coupled the mass and energy transport equations with the chemical equilibrium equation at each step of the calculation. Hosokawa et al. (2011) proposed a model for multispecies diffusion (Nernst-Planck-Poisson) by considering the chemical reactions between cement hydrates and the pore solution (coupling phase equilibrium model in PHREEQC externally). Multispecies transport can be simulated in PHREEQC only by using the phaseequilibrium and multi-component diffusion modules (Elakneswaran et al. 2010; Kari et al. 2013). However, in the existing models, different transport parameters and physicochemical properties of the cementitious material such as cement hydrates, porosity, etc. have to be estimated in advance as model inputs. Furthermore, these models did not couple the hydration and micropore structure formation models with the reactive transport models. Some thermodynamic models are available in literature to simulate the hydration of cement particles; these include a detailed thermodynamic reaction between cement hydrates and an aqueous solution (Lothenbach and Winnefeld 2006; Lothenbath 2010a; Lothenbach et al. 2010b). However, a detailed ionic transport is missing in these models.

Therefore, it is important to incorporate the hydration of cement particles, micro-pore structure development, multispecies transport, degradation phenomena due to ingress of detrimental ions, etc. into a single framework to simulate the behaviour of concrete structures in aggressive environments. A multi-scale chemo-physics model, which was developed in the Concrete Laboratory at the University of Tokyo Japan, can be used to predict the state of concrete from its birth over its entire life (Maekawa et al. 2009). The model is able to predict the performance of a concrete structure in aggressive envi- 
ronments. However, for a very accurate prediction, additional mechanisms and processes affecting the performance need to be included in the multi-scale model.

The aim of this study is to enhance the multi-scale chemo-physics model to increase its simulation capability and to predict the long-term performance of cementitious materials in aggressive aqueous environments. The Durability COncrete Model (DuCOM), which is the main part of the multi-scale chemo-physics model (Maekawa et al. 2009), and the geochemical transport code PHREEQC, which is designed to perform a variety of geochemical calculations including equilibrium between minerals and solution, ion exchanges, surface complexes, solid solution, and gases, (Appelo and Postma 2009; Parkhust and Appelo 1999) were coupled to achieve this purpose. Figure 1 provides an overview of DuCOM and the PHREEQC and their relations to the current research target. The coupled model performs various simulations simultaneously for the input of initial composition of cement, mix proportions, boundary conditions, thermodynamic database, etc., and the necessary data between DuCOM and PHREEQC are exchanged internally for the analyses. The objective of this study is not only to couple PHREEQC with DuCOM but also to add more ionic transport and equilibrium models $\left(\mathrm{HCO}_{3}, \mathrm{SO}_{4}, \mathrm{OH}, \mathrm{Mg}, \mathrm{Al}, \mathrm{Si}, \mathrm{Na}\right.$, and $\left.\mathrm{K}\right)$ as well as to consider the multispecies effect among the ions. The coupled model can simulate the hydration of ce- ment particles, micro-pore structure formation, moisture equilibrium and transport, transport of multispecies, interaction of aqueous species with cement hydrates, etc. simultaneously. Further, the coupled model can predict the spatiotemporal variation of the physical and chemical properties of the materials as well as determine the chemical degradation due to ingress of detrimental ions. It has been known that dissolution and/or precipitation of cement hydrates and minerals as a result of chemical reactions alter the micro-pore structure of cementitious materials and consequently change the effective diffusion coefficient of ions. This effect is taken into account in the coupled model.

The basic theory behind the ionic transport and thermodynamic reactions, coupling procedures of DuCOM and PHREEQC, and the framework of the coupled model are presented in this paper. The simulation results are compared with the experimental data available in literature to provide more validation to the coupled model. The significance of complete coupling of the DuCOM and PHREEQC models in evaluating the longterm performance of cementitious materials in aggressive environments is addressed in the last section.

\section{Model description}

PHREEQC has been integrated with other programs to perform geochemical calculations. The new IPhreeqc

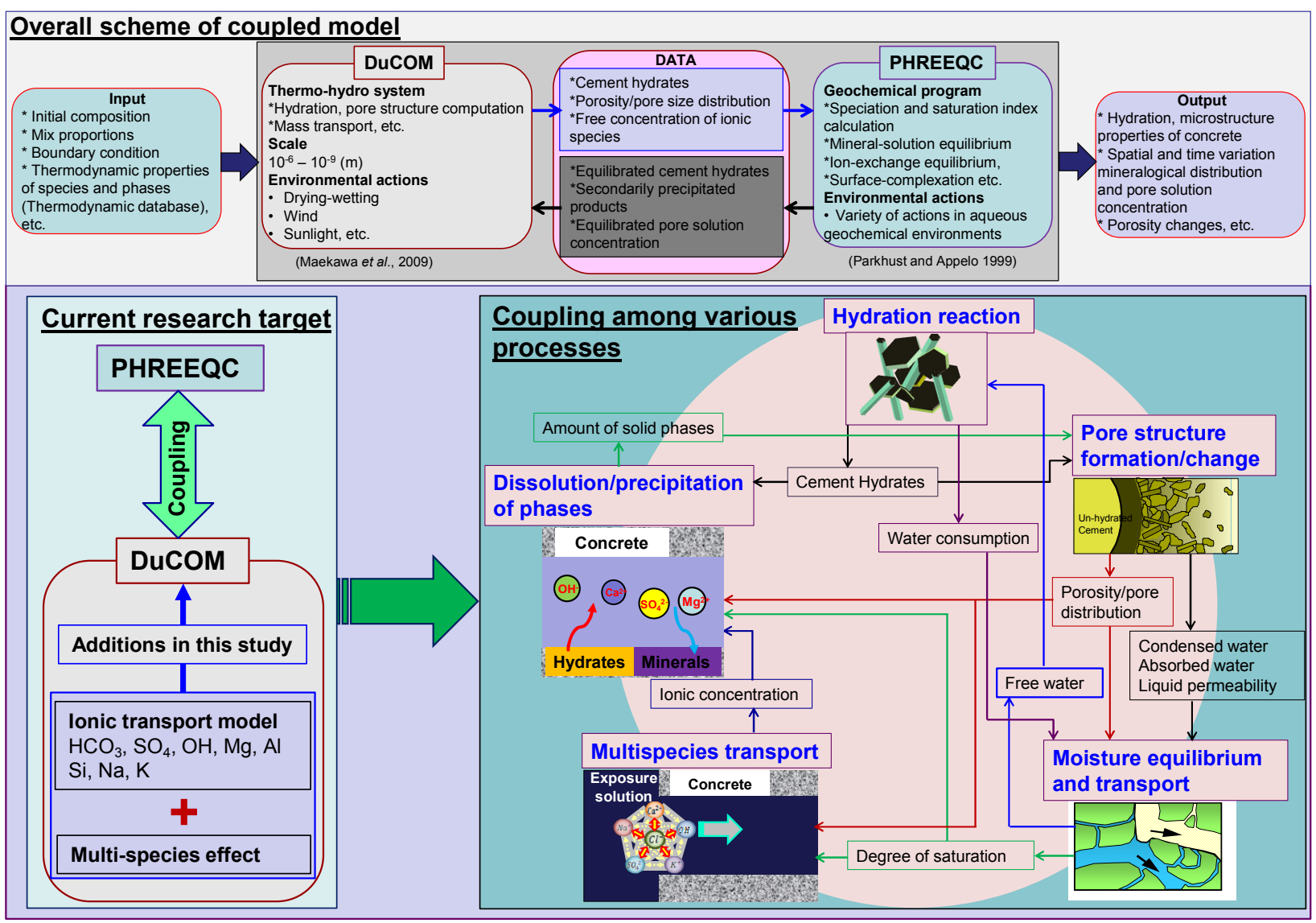

Fig. 1 Overview of the models and their relations to current research. 
module is designed for coupling PHREEQC with other programming languages [Charlton et al., 2011], and PHREEQC can run without reading or writing files. Data transfer occurs through the internal computer memory between PHREEQC and the other program. This type of process is advantages from the viewpoints of the calculation time and programming because IPhreeqc preserves the computed results between time steps rather than redefining PHREEQC for each time step. IPhreeqc provides direct access to geochemical processes in PHREEQC through a library. It has been proved that DuCOM can predict the hydration, micro-pore structure formation, ionic transport in cementitious materials, etc. (Maekawa et al. 2009). However, the current version of DuCOM cannot perform geochemical reactions simultaneously with the above calculations. On the other hand, PHREEQC can perform geochemical and speciation calculation (Appelo and Postma 2009; Parkhust and Appelo 1999). Furthermore, it can perform the same kind of calculations in cementitious materials as well (Elakneswaran et al. 2010; Hosokawa et al. 2011; Kari et al. 2013). However, PHREEQC cannot predict the hydration or micro-pore structure formation in cementitious materials. In addition, it requires many parameters such as the physical and chemical properties (amount of cement hydrates, pore solution composition, etc.) as model inputs. Therefore, DuCOM needs to be coupled with PHREEQC to perform a wide range of calculations and to predict the performance of cementitious materials in aggressive environments. In this section, a set of equations that need to be solved for finite element analysis and coupling procedures are briefly described.

\subsection{Governing mass balance equation}

The ions are free to move in the liquid medium or to bind with the solid phase. The governing equation in this phenomenon can be expressed as follows (Maekawa et al. 2009; Ishida et al. 2009):

$$
\frac{\partial\left(\phi \cdot S \cdot C_{i}\right)}{\partial t}+\operatorname{div} J_{i}-Q_{i}=0
$$

where $\Phi=$ porosity; $S=$ degree of saturation of porous media; $C_{i}=$ concentration of an ion in pore solution; $J_{i}=$ total flux of an ion; and $Q_{i}=$ sink term.

In Eq. (1), the first term represents the rate of change in the total amount of ions per unit time and volume; the second term gives the total flux due to both diffusion and advection; and the last term, which is called the sink or source term, represents the rate of removed, dissolved, precipitated, or generated ions by reactions. Eq. (1) needs to be solved for the numerical analysis of ionic ingress into cementitious materials.

\subsection{Transport of multispecies}

The ions in a solution have an effect from the coexisting ions. Thus, the diffusion coefficients of cations, anions, and neutral species in a solution have different values. The diffusive flux of ions considering the concentration and electrical potential gradients, and the chemical activity effects in a porous media can be expressed as follows (Nernst-Plank equation) (Appelo et al. 2007):

$$
J_{i t a t}=-\phi \cdot S \cdot\left(\frac{D_{i}}{\Omega} \cdot \delta\right) \cdot\left[\frac{\partial \ln \left(\gamma_{i}\right)}{\partial \ln \left(C_{i}\right)}+1\right] \frac{\partial C_{i}}{\partial x}-\phi \cdot S \cdot \frac{F}{R T} Z_{i} C_{i}\left(\frac{D_{i}}{\Omega} \cdot \delta\right) \frac{\partial \psi}{\partial x}(2)
$$

where $D_{i}=$ diffusion coefficient of an ion $\left(\mathrm{m}^{2} / \mathrm{s}\right) ; \delta=$ constrictivity; $\Omega=$ tortuosity; $\gamma_{i}=$ activity coefficient of an ion; $F=$ Faraday's constant $(96,488.46 \mathrm{C} / \mathrm{mol}) ; R=$ ideal gas constant $(8.3143 \mathrm{~J} / \mathrm{mol} . \mathrm{K}) ; T=$ absolute temperature $(\mathrm{K}) ; Z_{i}=$ ion valance; and $\psi=$ electrical potential (V)

The diffusion coefficient of an ion, $D_{i}$, in free water is expressed by (Maekawa et al. 2009; Ishida et al. 2009),

$$
\begin{aligned}
& D_{i}=R \cdot T \cdot \frac{\lambda_{i}}{z_{i}^{2} \cdot F^{2}} \\
& \lambda_{i}=\lambda_{i_{-} 25} \cdot \exp \left\{-1700\left(\frac{1}{T}-\frac{1}{298}\right)\right\}
\end{aligned}
$$

where $\lambda_{i}=$ conductivity of an ion $\left(\mathrm{Sm}^{2} / \mathrm{mol}\right)$; and $\lambda_{i_{-} 25}=$ conductivity of an ion at $25^{\circ} \mathrm{C}\left(\mathrm{Sm}^{2} / \mathrm{mol}\right)$

The activity coefficients, $\gamma_{i}$, are calculated according to the extended Debye-Huckel (Appelo and Postma 2009):

$$
\log \gamma_{i}=-\frac{A z_{i}^{2} \sqrt{I}}{1+B a_{i} \sqrt{I}}+b_{i} I
$$

where $A$ and $B=$ temperature dependent coefficients; and $a_{i}$ and $b_{i}=$ ion-specific fit parameters. The ionic strength, $I$, can be described as,

$$
I=\frac{1}{2} \sum_{i=1}^{n} c_{i} z_{i}^{2}
$$

The electrical potential gradient is caused by the different mobility of ions in the solution. If there is no electrical current,

$$
\sum_{i} J_{i} \cdot Z_{i}=0
$$

The zero-charge flux permits one to determine the electrical potential gradient as a function of the other term in Eq. (2). The electrical potential gradient is given as,

$$
\frac{\partial \psi}{\partial x}=-\frac{R T}{F} \cdot \frac{\sum_{i}\left\{\left[Z_{i} \cdot D_{i}\right] \cdot\left[\frac{\partial \ln \left(\gamma_{i}\right)}{\partial \ln \left(C_{i}\right)}+1\right] \cdot \frac{\partial C_{i}}{\partial x}\right\}}{\sum_{i} Z_{i}^{2} \cdot C_{i} \cdot D_{i}}
$$

By substituting Eq. (8) into Eq. (2), the diffusive flux of an ion in a porous medium is expressed as, 


$$
\begin{aligned}
& J_{i}=-\phi \cdot S \cdot\left(\frac{D_{i}}{\Omega} \cdot \delta\right) \cdot\left[\frac{\partial \ln \left(\gamma_{i}\right)}{\partial \ln \left(C_{i}\right)}+1\right] \frac{\partial C_{i}}{\partial x} \\
& +\phi \cdot S \cdot\left(\frac{D_{i}}{\Omega} \cdot \delta\right) \cdot Z_{i} C_{i} \frac{\sum_{j=1}^{n}\left\{\left[Z_{j} \cdot D_{j}\right] \cdot\left[\frac{\partial \ln \left(\gamma_{j}\right)}{\partial \ln \left(C_{j}\right)}+1\right] \cdot \frac{\partial C_{j}}{\partial x}\right\}}{\sum_{j=1}^{n} Z_{j}^{2} \cdot C_{j} \cdot D_{j}}
\end{aligned}
$$

where the subscript $j$ is introduced to show that these species are for potential terms.

\subsection{Chemical equilibrium model}

This model is used to define the amount of pure phases that can react reversibly with an aqueous phase to achieve equilibrium. Thermodynamic modelling has been used in a cement system for various purposes (Lothenbath 2010a) such as (i) calculating the stable phases based on the solution composition, (ii) modelling the influence of the initial composition on the final resulting stable phases, (iii) simulating the changes with hydration, and (iv) integrating with the transport model for understanding the interaction with the environment. The equilibrium reactions are expressed by mass-action equations, and therefore, the pure-phase equilibrium can be written as (Appelo and Postma 2009),

$$
K_{p}=\prod_{i}\left(\gamma_{i} c_{i}\right)^{n_{i, p}}
$$

where $K_{p}=$ thermodynamic equilibrium constant for the phase $p$; and $n_{i, p}=$ stoichiometric coefficient of ion $i$ in the phase $p$. The thermodynamic equilibrium constant, $K_{p}$, at a given temperature $T$ can be expressed as,

$$
K_{p}=\exp \left(-\frac{\Delta_{r} G_{T}^{0}}{R T}\right)
$$

where $\Delta_{r} G_{T}{ }^{0}$ is the standard Gibbs energy of reaction at temperature $T$. It is given as,

$$
\Delta_{r} G_{T}^{0}=\sum \Delta_{f} G_{T, \text { products }}^{0}-\sum \Delta_{f} G_{T, \text { reac } \tan t s}^{0}
$$

Here $\Delta_{f} G_{T}{ }^{0}$ is the Gibbs free energy of formation for a species at a given temperature $T$. Explanations of the basic principles of the thermodynamic calculations and chemical reactions are detailed in textbooks (Parkhust and Appelo 1999; Appelo and Postma 2009). When a pure phase is no longer in equilibrium with a solution, it will dissolve or precipitate to achieve equilibrium or will dissolve completely. The composition of the equilibrating solution provides information regarding the stability of the products. Comparing the activity product of ions in the solution involved in the reactions with solubility products gives the degree of over or under saturation of solids with respect to the equilibrated solution. If the activity product of ions is greater than the solubility product or equilibrium constant, some of the ions in the solution start to precipitate. Dissolution occurs in the reverse situation. The sink term, $Q_{i}$, in Eq. (1) accounts for the consumption or release of ion $i$ owing to thermodynamic reactions (herein, after the PHREEQC calculation). At an arbitrary stage, the sink term can be expressed as follows:

$$
Q_{i}=q_{i}-q_{i}^{e}
$$

where $q_{i}=$ the amount of ion $i$ prior to thermodynamic reactions $\left(\mathrm{mol} / \mathrm{m}^{3}\right)$; and $q_{i}^{e}=$ the amount of ion $i$ after the thermodynamic calculations $\left(\mathrm{mol} / \mathrm{m}^{3}\right)$.

\subsection{Pore structure modification}

It has been reported that the dissolution and/or precipitation of cement hydrates and minerals as a result of chemical reactions alter the micro-pore structure of cementitious materials. The existing micro-pore structure computation model in DuCOM is modified by considering the dissolution and/or precipitation of cement phase assemblages owing to thermodynamic equilibrium reactions. The micro-pore structure formation model is described in detail elsewhere (Maekawa et al. 2009); the main equations are described briefly here with slight modifications. In micro-pore structure formation model, at any stage of hydration, it is considered that the cement paste matrix contains hydrated products, unreacted cement particles, and large void spaces partially filled with water. The hydrated products include various phases such as C-S-H grains, portlandite, ettringite, monosulfate, and gypsum. Furthermore, the model assumed that C-S-H grains, ettringite, monosulfate, and gypsum as C-S-H gel. This assumption is necessary to determine the pores in the gel. The porosity of the cement paste matrix is divided into three main categories: interlayer, gel, and capillary porosity. Capillary porosity exists in the large inner space of power particles and is available for precipitation of the products during the hydration process, whereas gel and interlayer porosity exist in the interstitial spaces of C-S-H gel (Fig. 2). Interlayer and gel pores are the pores of C-S-H gel and are unavailable for hydrated products precipitation (Maekawa et al. 2009; Nakarai et al. 2006). In this study, the same assumptions and the categorization were adopted to calculate the porosities. At an arbitrary stage of hydration, the volume of the hydrated products

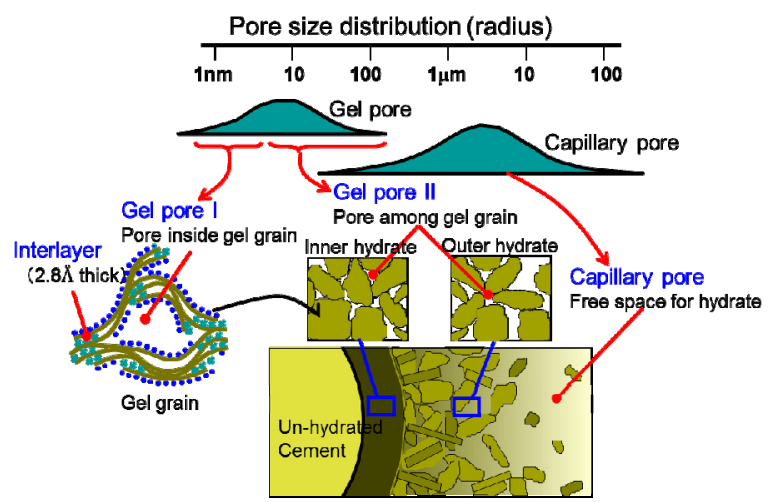

Fig. 2 Schematic representation of porosity component in cement hydrates [Maekawa et al. 2009]. 
$\left(\mathrm{m}^{3} / \mathrm{m}^{3}\right.$ of paste), $V_{s}$, in a unit volume of paste can be obtained as

$$
V_{s}=\frac{\alpha W_{p}}{1-\phi_{c h}}\left(\frac{1}{\rho_{p}}+\frac{\beta}{\rho_{w}}\right)
$$

where $\alpha=$ degree of hydration (-); $W_{p}=$ weight of powder materials per unit paste volume $\left(\mathrm{kg} / \mathrm{m}^{3}\right.$ of paste); $\phi_{c h}=$ characteristic porosity of hydrated products (-); $\rho_{p}$ $=$ density of powder materials $\left(\mathrm{kg} / \mathrm{m}^{3}\right) ; \beta=$ amount of chemically combined water per unit weight of hydrated powder material $(-)$; and $\rho_{w}=$ density of chemically combined water $\left(\mathrm{kg} / \mathrm{m}^{3}\right)$. At an arbitrary stage, the net volume of the C-S-H gel in a unit volume of paste, $V_{C-S \text { - }}^{n}$ $H$, can be calculated from C-S-H gel produced by the hydration of cement particles and volumetric change of $\mathrm{C}-\mathrm{S}-\mathrm{H}$ grains as a result of thermodynamic equilibrium reaction. It can be expressed as follows:

$$
\begin{aligned}
& V_{C-S-H}^{n}=V_{s}-V_{C H}+\Delta V_{C-S-H} \\
& \Delta V_{C-S-H}=\Delta m_{C-S-H} * M_{C-S-H} \\
& \Delta m_{C-S-H}=m_{C-S-H}^{n}-m_{C-S-H}^{n-1}
\end{aligned}
$$

where $V_{C H}$, volume of portlandite in a unit volume of paste produced during the hydration of cement particles $\left(\mathrm{cm}^{3}\right) ; \Delta V_{C-S-H}=$ volumetric change of C-S-H grains in a unit volume of paste as a result of thermodynamic equilibrium reactions $\left(\mathrm{cm}^{3}\right) ; \Delta m_{C-S-H}=$ molar change of C-S$\mathrm{H}$ grains in a unit volume of paste as a result of thermodynamic equilibrium reactions (mol); $M_{C-S-H}=$ molar volume of C-S-H grains $\left(\mathrm{cm}^{3} / \mathrm{mol}\right)$; and $m_{C-S-H}^{n}$ and $m^{n-}$ ${ }_{C-S-H}$ mole of C-S-H grains in a unit volume of paste in step $n$ and $n-1$ respectively (mol). As previously mentioned, the interlayer porosity $\left(\phi_{l}\right)$ and gel porosity $\left(\phi_{g}\right)$ exist in the C-S-H gel, and they can be computed from the net volume of the C-S-H gel.

$$
\begin{aligned}
& \phi_{l}=\frac{t_{w} s_{l} \rho_{g} V_{C-S-H}^{n}}{2} \\
& \phi_{g}=V_{C-S-H}^{n} \phi_{c h}-\phi_{l}
\end{aligned}
$$

where $t_{w}=$ interlayer thickness; $s_{l}=$ specific area of the interlayer; and $\rho_{g}=$ dry density of C-S-H gel. The dissolved and/or precipitated hydrated products and secondarily formed minerals affect the capillary porosity. The capillary porosity, $\left(\phi_{c}\right)$, resulting from hydration and thermodynamic equilibrium reactions can be obtained as:

$$
\phi_{c}=1-V_{s}-(1-\alpha)\left(W_{p} / \rho_{p}\right)-\sum_{p=1}^{k} \Delta V_{p}
$$

where $\Delta V_{p}=$ volumetric change of a phase $p(\mathrm{C}-\mathrm{S}-\mathrm{H}$ grains, portlandite, ettringite, monosulfate, and gypsum, etc.) in a unit volume of paste as a result of thermodynamic equilibrium reactions $\left(\mathrm{cm}^{3}\right)$. This is calculated by the same method as that for C-S-H grains given in Eqs. (16) and (17). The modified porosity directly influences the transport of multispecies by modifying the porosity values in the governing equation (Eq. (1)). It is assumed that there is no ionic transport into the interlayer pores of the cement matrix. Therefore, the porosity, $\phi$, in Eq. (1) is the sum of the gel and capillary porosities.

\subsection{Framework and coupling procedure of model}

Herein, DuCOM is coupled with IPhreeqc (hereafter called PHREEQC) using the FORTRAN programming language to solve multispecies reactive transport problems in cementitious materials. The coupled model retains all the capabilities of both DuCOM and PHREEQC, and it can be used not only for multispecies reactive transport problems but also for other purposes. A basic framework of DuCOM coupled with PHREEQC is shown in Fig. 3. As shown in the figure, DuCOM consists of several sub-models that work together and interlink. PHREEQC was inserted into DuCOM as a sub-model to perform speciation and geochemical calculation after pore pressure computation model as well as in each ion equilibrium and transport model. In the coupled model, DuCOM performs hydration, microstructure formation/change, and moisture and multispecies transport calculation whereas PHREEQC performs only thermodynamic equilibrium calculations. Therefore, every sub-model in the framework satisfies the governing equation (Eq. (1)) for finite element method (FEM) calculation through continuous iterations. Each gauss point in the finite element of DuCOM is represented by a single batch reactor for PHREEQC that contains minerals and solution species, and PHREEQC performs speciation and geochemical calculations.

Hydration and microstructure properties of powder materials are calculated in the first three sub-models, and the necessary data to perform thermodynamic equilibrium calculation between cement hydrates and pore solution are transferred to PHREEQC sub-model $\left(4^{\text {th }}\right.$ sub-model in the framework). In the ions equilibrium and transport models $\left(5^{\text {th }}\right.$ - last sub-model in the framework), both multispecies transport and thermodynamic equilibrium between cement hydrates and solution calculations were performed to determine the equilibrated solid phases and ionic concentration. As previously stated, PHREEQC was incorporated into each ion equilibrium and transport model to do thermodynamic equilibrium calculation. The information on consumed/released of ion as a result of thermodynamic equilibrium calculation is transferred to solve Eq. (1) for the determination of free concentration of an ion in a sub-model. The output of PHREEQC sub-model or an ion equilibrium and transport model is given to next sub-model in the framework for thermodynamic equilibrium and/or multispecies transport calculations. This coupling provides the internal data transfer between DuCOM and PHREEQC while they are running con- 


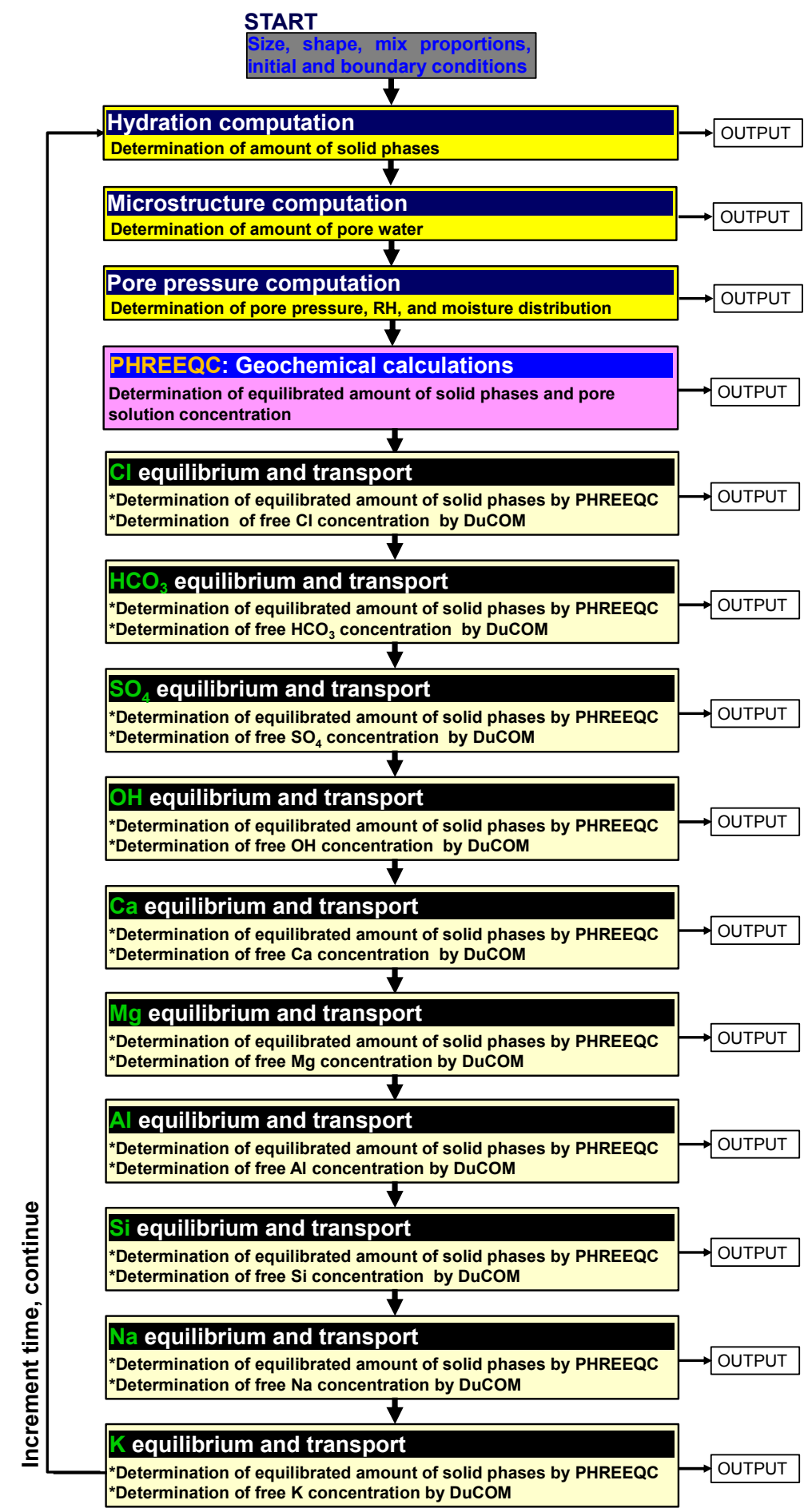

Fig. 3 Framework of coupled DuCOM and PHREEQC. PHREEQC has incorporated into the system as a model after hydration and microstructure computation as well as in each ionic transport model.

currently. Therefore, either DuCOM or PHREEQC neither writes nor reads files for coupling. In the framework, the sub-models are in series and output of a submodel is passed to following sub-models in that time step or transferred to previous sub-models in the next time step to solve multispecies reactive transport equation. The numerical error induced by this method can be negligible with smaller time step and mesh size.
Figure 4 shows the coupling and calculation procedures in DuCOM and PHREEQC. At the beginning of each time step, hydration computation is performed in DuCOM system based on the input of clinker composition, mix proportions, and boundary conditions. Pore structure formation and/or pore structure change is computed based on the cement hydration and the amount of dissolved/precipitated phases as a result of 


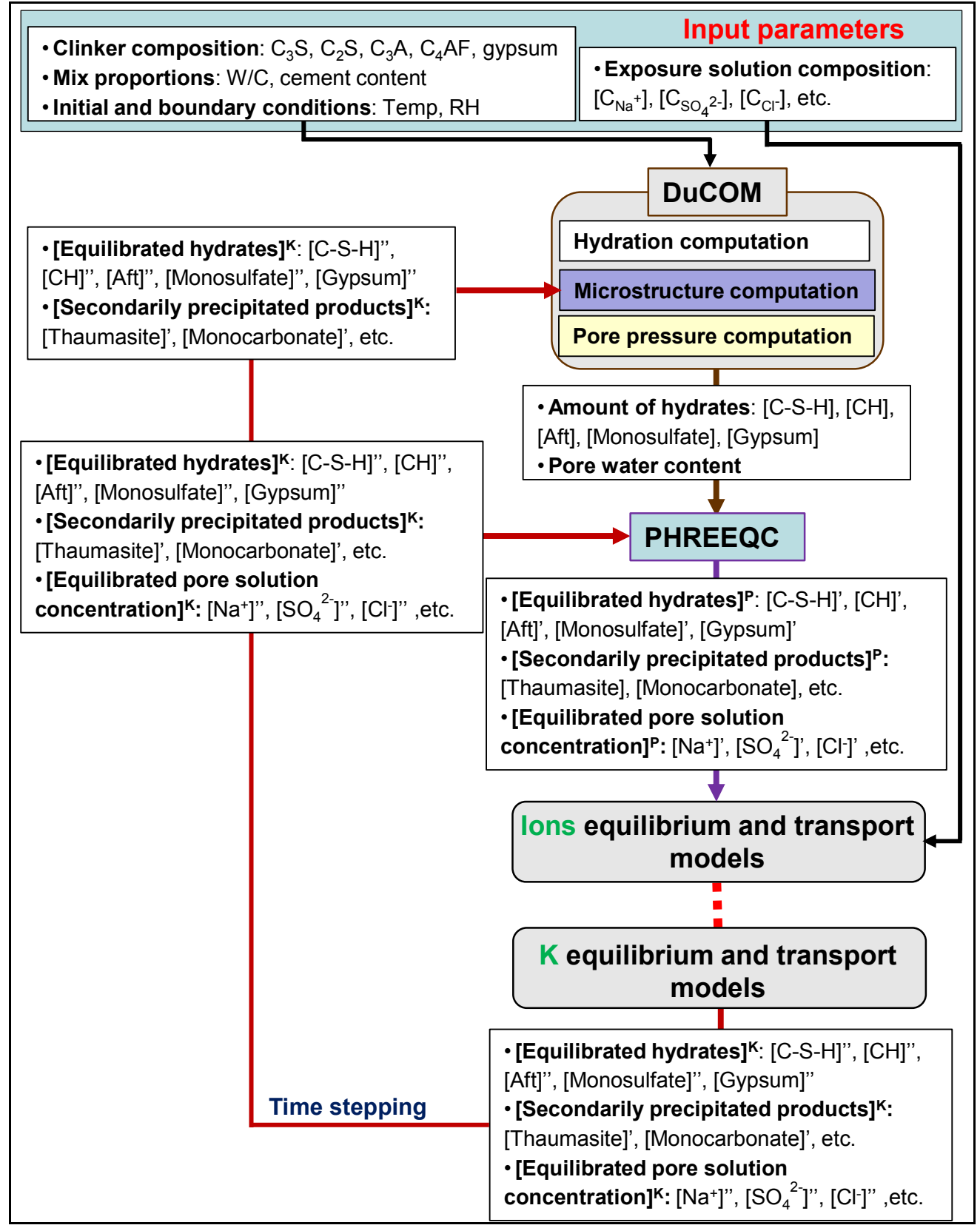

Fig. 4 Schematic diagram of coupling DuCOM and PHREEQC.

thermodynamic equilibrium (as described in section 2.4). The computed cement hydrates (Amount of hydrates: [C-S-H], [CH], [Aft], [Monosulphate], [Gypsum]) as a result of cement hydration, porosity $\left(\phi_{g}+\phi_{c}\right)$, pore distribution, and pore water content together with dissolved/precipitated amount of hydrates and products $\left(\Delta m_{p}\right)$ and the ionic concentration are passed to "PHREEQC: Geochemical calculation model". As shown in Fig. 3, the output of a sub-model is transferred to the following sub-models in that time step because of the sequence of sub-model in the framework. Therefore, the necessary input values such as the amount of dissolved/precipitated hydrates and products and ionic concentration for "PHREEQC: Geochemical calculation model" are the values of preceding time step from the last sub-model in the framework ("K equilibrium and transport model" in Fig. 3). "PHREEQC: Geochemical calculation model" performs thermodynamic equilibrium calculations, and the output of equilibrated hydrates ([Equilibrated hydrates] $]^{\mathrm{P}}:$ [C-S-H]', [CH]', [Aft]', [Monosulphate]', [Gypsum]'), secondarily precipitated products ([Secondarily precipitated products $]^{\mathrm{P}}$ : [Thaumasite], [Monocarbonate], etc.), and equilibrated pore solution concentrations ([Equilibrated pore solution concentration $]^{\mathrm{P}}$ : $\left[\mathrm{Na}^{+}\right]$', $\left[\mathrm{SO}_{4}^{2-}\right]$ ', $\left[\mathrm{Cl}^{-}\right]$', etc.) are given to next sub-model (herein " $\mathrm{Cl}$ equilibrium and transport model").

Figure 5 shows the conceptual approach for data exchange between DuCOM and PHREEQC at each time step in the "ions equilibrium and transport model". The 


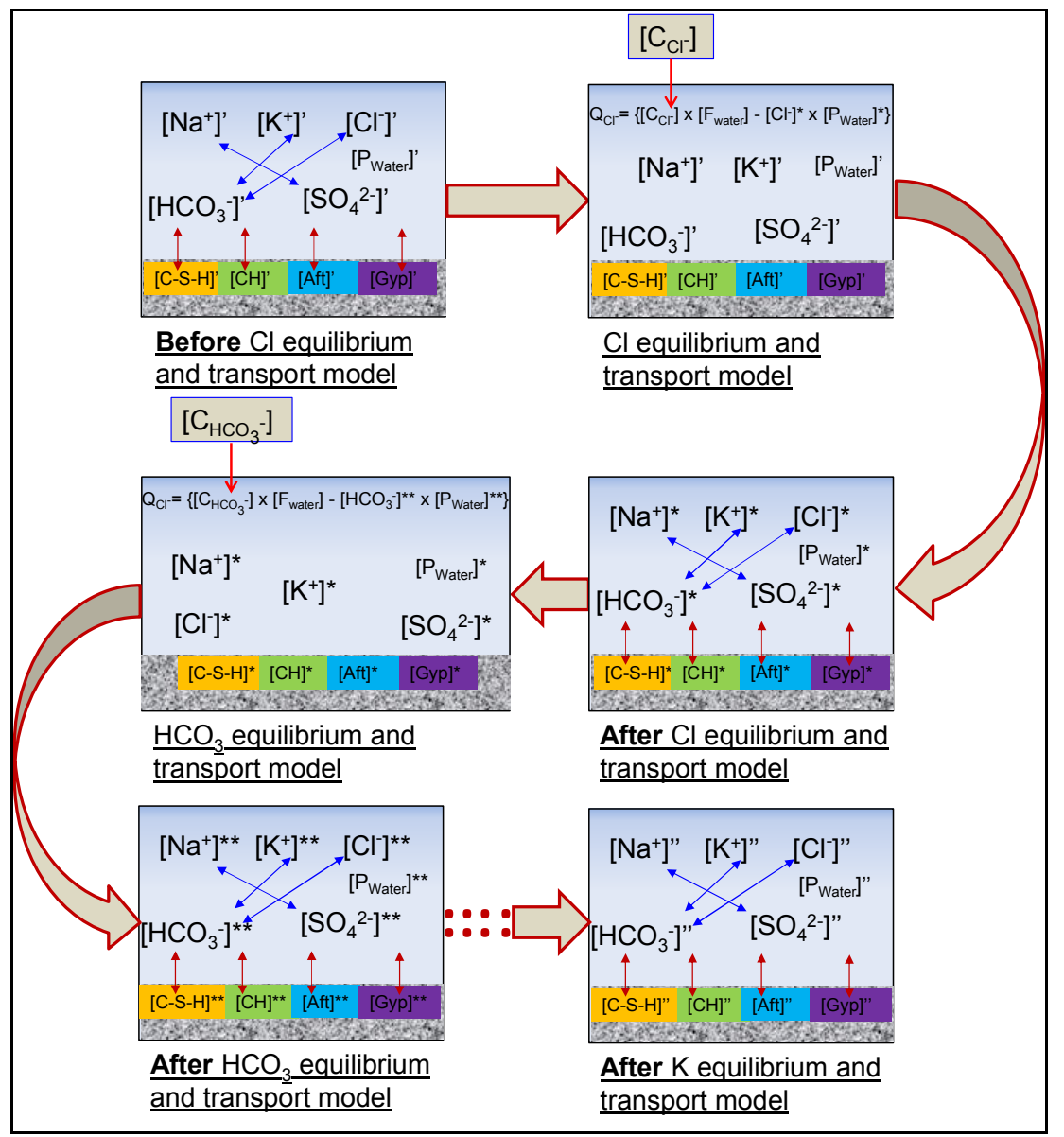

Fig. 5 Conceptual coupling of DuCOM with PHREEQC at each time step.

figure illustrates that the ions in the pore solution (such as $\left(\left[\mathrm{Na}^{+}\right]^{\prime},\left[\mathrm{SO}_{4}{ }^{2-}\right],,\left[\mathrm{Cl}^{-}\right]\right.$, , etc.) are in equilibrium with cement hydrates and phases (such as ([C-S-H]', [CH]', [Aft]', [Monosulphate]', [Gypsum]', etc.) before 'Cl equilibrium and transport model" because those are the outputs of "PHREEQC: Geochemical calculation model". The same concentration of ions and the amount of cement hydrates are given to " $\mathrm{Cl}$ equilibrium and transport model" as input parameters for thermodynamic equilibrium calculations except equilibrated $\mathrm{Cl}^{-}$ $\left(\left[\mathrm{Cl}^{-}\right]^{\prime}\right)$ because the free concentration of chloride $\left(\left[\mathrm{C}_{\mathrm{Cl}}{ }^{-}\right.\right.$ ]) in the sub-model is the degree of freedom to be solved in the governing equation (Eq. (1)). The free concentration in the sub-model is used for thermodynamic calculation. In order to solve the governing equation, the diffusive flux of $\mathrm{Cl}^{-}$is calculated by solving Eq. (9) together with Eq. (5) and Eq. (6) where the concentrations of other species to solve Eq. (6) and Eq. (9) are the free concentration of ions given from the respective sub-models, and the sink term $\left(Q_{C l}^{-}\right)$, consumed/released of $\mathrm{Cl}^{-}\left(\triangle^{C l}\right.$ solid $)$ as result of thermodynamic calculation, is calculated as follows:

$$
Q_{C l^{-}}=\Delta_{\text {Solid }}^{C l}=\left\{\left[C_{C^{-}}\right] \times\left[F_{\text {water }}\right]-\left[C l^{-}\right]^{*} \times\left[P_{\text {water }}\right]^{*}\right\}
$$

where $\left[F_{\text {water }}\right]=$ amount of free water for ionic transport calculated in "Microstructure and pore pressure computation models"; $\left[\mathrm{Cl}^{*}\right]^{*}=$ concentration of $\mathrm{Cl}^{-}$after thermodynamic equilibrium calculation in " $\mathrm{Cl}$ equilibrium and transport model"; $\left[P_{\text {water }}\right]^{*}=$ amount of pore water after thermodynamic equilibrium calculation in " $\mathrm{Cl}$ equilibrium and transport model". Once the governing equation is solved for $\mathrm{Cl}^{-}$, the output values of the equilibrated pore solution concentration ([Equilibrated pore solution concentration $]^{\mathrm{Cl}}:\left[\mathrm{Na}^{+}\right]^{*},\left[\mathrm{~K}^{+}\right]^{*},\left[\mathrm{Cl}^{-}\right]^{*}$, etc.) and the equilibrated cement hydrates ([Equilibrated hydrates $]^{\mathrm{Cl}}$ : [C-S-H$]^{*},[\mathrm{CH}]^{*}$, [Aft $]^{*}$, etc.) of " $\mathrm{Cl}$ equilibrium and transport model" are given to next sub-model (" $\mathrm{HCO}_{3}$ equilibrium and transport model") as input parameters for thermodynamic equilibrium calculation, and determined free $\mathrm{Cl}^{-}\left(\left[C_{C l}{ }^{-}\right]\right)$will be used in other sub-models for Eq. (6) and Eq. (9). It is important to note that the output values after "PHREEQC: Geochemical calculation model" (Ex. ([Equilibrated hydrates $]^{\mathrm{P}}$, [Equilibrated pore solution concentration] $]^{\mathrm{P}}$, etc.) are different those of " $\mathrm{Cl}$ equilibrium and transport model" (Ex. ([Equilibrated hydrates $]^{\mathrm{Cl}}$, [Equilibrated pore solution concentration $]^{\mathrm{Cl}}$, etc.) because the presence of free $\mathrm{Cl}\left(\left[\mathrm{C}_{\mathrm{Cl}}\right]\right)$ ) from exposure solution. The data transfer processes between sub-models are continued until the last sub-model (" $\mathrm{K}$ equilibrium and transport model" in Fig. 3). The output values of " $\mathrm{K}$ equilibrium and transport model" such as equilibrated hydrates 
([Equilibrated hydrates $]^{\mathrm{K}}$ : [C-S-H] ", [CH]", [Aft]", [Monosulphate]", [Gypsum]"), secondarily precipitated products ([Secondarily precipitated products $]^{\mathrm{K}}$ : [Thaumasite]', [Monocarbonate]', etc.), and equilibrated pore solution concentration ([Equilibrated pore solution concentration $]^{\mathrm{K}}$ : $\left[\mathrm{Na}^{+}\right] ",\left[\mathrm{SO}_{4}^{2-}\right] ",\left[\mathrm{Cl}^{-}\right] "$,etc.) are given to "Microstructure and pore pressure computation models" and "PHREEQC: Geochemical calculation model" in the following step (see Fig. 3 and Fig. 4). These outputs update the amount of cement hydrates and other solid products and the porosity (as described in section 2.4). These calculations steps are continued until total time.

It can be seen that the output of a sub-model resulting from thermodynamic equilibrium calculation is passed to the next sub-model in the framework as the input for thermodynamic equilibrium calculations. However, the free concentration of an ion $\left(\left[C_{i o n}\right]\right)$ is calculated in the sub-model according to the governing equation, and the determined free concentration of an ion is used for thermodynamic equilibrium calculation instead of the output of the previous sub-model. This approach enables the thermodynamic equilibrium calculation to be performed during the iteration loop, and required data are transferred via the sink term to solve the governing equation. It is emphasized that the transport equations (given in section 2.2) are solved simultaneously in DuCOM not divided between DuCOM and PHREEQC, and the role of PHREEQC in the sub-models is to provide the amount of consumed/released ion as a sink term to solve Eq. (1). The main advantage of the current coupled system is the complete coupling between a full suite of geochemical reactions and multispecies transport. The coupled model does not need physical or chemical properties in advance as the input data to the model because they are calculated automatically in the model. The coupled model described here can be used to predict the hydration of cement particles, multispecies transport, and geochemical reactions in cementitious materials simultaneously. This strong coupling of geochemical processes with physical properties provides more information regarding the long-term performance of cementitious materials in aggressive environments.

\section{Simulation results and discussions}

\subsection{Experimental verification}

The validity of the coupled model was established by comparing the simulated results from the coupled model with the experimental data available in literatures in order to predict the long-term performance of cementitious materials. The thermodynamic properties of various minerals and aqueous species were used as reported in the BRGM database, Thermoddem (Blanc et al. 2010a, 2010b), available at http://thermoddem.brgm.fr, and CEMDATA07 (Lothenbach and Winnefeld 2006). The values in CEMDATA07 were converted into a suitable format for PHREEQC. Various simulations have been carried out with the proposed model. It provides many details such as the hydration of cement particles, microstructure formation, pore solution concentration, ionic profiles during transport, mineralogical distributions, etc. as a function of time and depth.

\subsubsection{Composition of cement hydrates}

The coupled model was used to predict the hydrating ordinary Portland cement (OPC) particle. The hydration model in the framework has been described in detail elsewhere (Maekawa et al. 2009). The simulation result for hydrating OPC paste with water to cement ratio (W/C) of 0.5 is shown in Fig. 6. In addition to some unhydrated cement, calcium silicate hydrates (C-S-H), ettringite (Aft), and monosulphate are the main phases in the hydrated OPC. It can further be seen that the formation of monosulphate correlates with the disappearance of ettringite. The amount of C-S-H and portlandite continues to increase slowly with time, but the formation of monosulphate does not change with time at later hydration time. Quantitative verification of the hydrated products is necessary to evaluate the performance of cementitious materials in aggressive environments.

The simulated hydrated products are compared with experimental data reported in ref. (Lothenbach et al. 2008). The simulation was performed for OPC paste with W/C of 0.4 using the same cement composition and other experimental conditions adopted in ref. (Lothenbach et al. 2008). The simulated results for hydrated OPC samples show the same kind of phases as observed by X-ray diffraction (XRD) Rietveld analysis and thermo gravimetric analysis (TGA) (Lothenbach et al. 2008). The comparison of experimentally (XRD and TGA) determined portlandite with the simulated results is shown in Fig. 7. The calculated ettringite as a function of hydration time compared with the experimental one is shown in Fig. 8. The model predicts a lower amount of ettringite than the XRD measurement. It is noteworthy that the formation of ettringite in the hydration model is attributed as the reaction between aluminate and gypsum as well as the reaction between ferrite and gypsum (Maekawa et al. 2009). The ettringite formation is stopped when there is no more gypsum. Consequently, the unreacted aluminate and ferrite react with

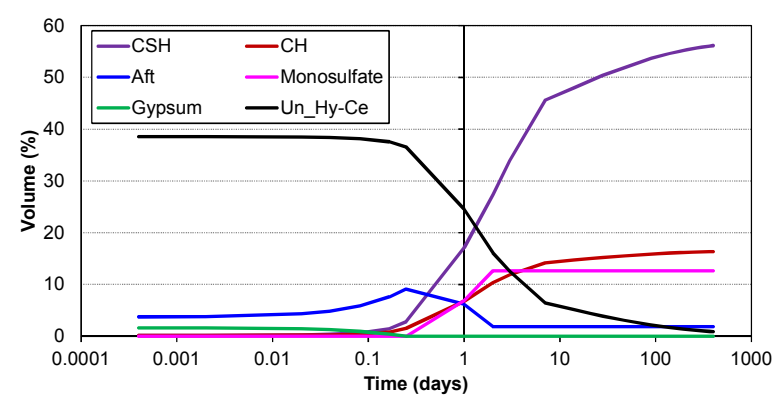

Fig. 6 Simulated results for changes of phases as a function of hydration time for OPC with W/C of 0.5. CSH: $\mathrm{C}-\mathrm{S}-\mathrm{H}$ with $\mathrm{Ca} / \mathrm{Si}$ of 1.6 ; $\mathrm{CH}$ : Portlandite; Aft: Ettringite; Un-Hy-Ce: Un-hydrated cement. 


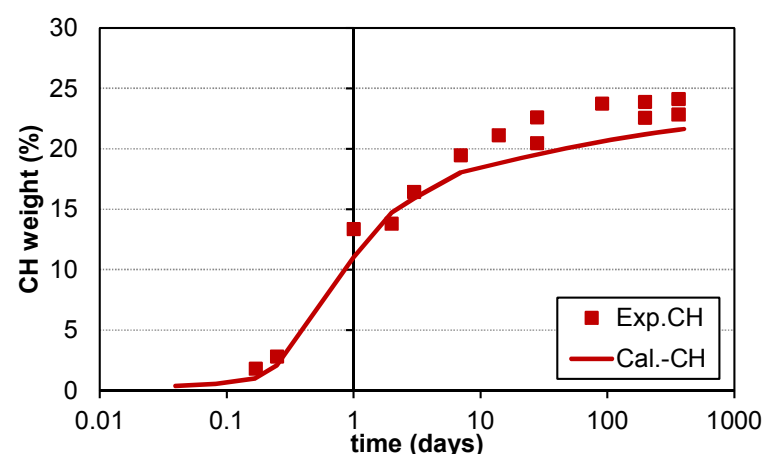

Fig. 7 Comparing the amount of portlandite deduced by XRD/Rietveld analysis and TGA [Lothenbach et al. 2008] with calculated results as a function of hydration time.

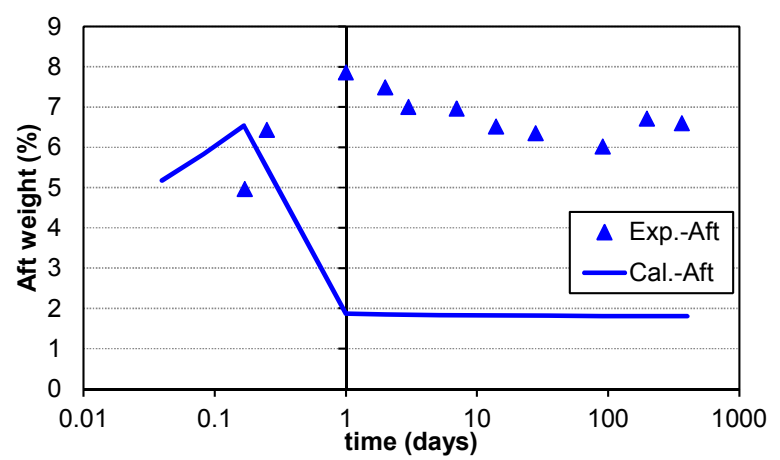

Fig. 8 Comparing the amount of ettringite deduced by XRD/Rietveld analysis [Lothenbach et al. 2008] with calculated results as a function of hydration time.

ettringite for the formation of monosulphate. The thermodynamic equilibrium between cement hydrates and pore solution produces a small amount of ettringite in the hydrated products. The XRD measurement at very early hydration time agrees with the model prediction, but the experimental results show a minor fraction in the dissolution of ettringite after one day. The AFm phases determined by XRD are certainly underestimated owing to their poor crystalline structure, relatively low amount, and lack of data concerning the structure (Matschei and Lothenbach 2007). Therefore, it is more appropriate to compare the total amorphous content $(\mathrm{C}-\mathrm{S}-\mathrm{H}+$ amorphous AFm) and AFm from XRD measurement with the summation of simulated C-S-H and monosulphate. The experimentally deduced amorphous content agreed very well with the simulated results for the summation of $\mathrm{C}$ $\mathrm{S}-\mathrm{H}$ and monosulphate as shown in Fig. 9. Apart from some discrepancies in ettringite, the quantities of hydrated phases as determined by XRD and TGA generally agreed well with the simulated results as a function of hydration time, indicating the predictive capabilities of the coupled model for hydration of OPC.

\subsubsection{Chemical composition of pore solution}

The concentration of alkali ions in the pore solution in a saturated condition can be calculated according to the method proposed by Taylor (detailed in ref. (Brouwers et al. 2003)). It is based on the mix proportion, chemical composition of cement, and hydration of cement. The calculation consists of the release of alkali ions from cement and its uptake by cement hydrates. When the release and uptake of alkali are known, the concentration of $\mathrm{Na}^{+}$and $\mathrm{K}^{+}$in the pore solution can be determined during hydration. The calculation method is described in ref. (Brouwers et al. 2003) and briefly explained in here for $\mathrm{Na}^{+}$. The same procedure is used to determine the $\mathrm{K}^{+}$concentration. The total concentration of $\mathrm{Na}^{+}$can be computed from the mass fraction and molecular weight as follows:

$$
N a_{T}=\frac{2 f_{\mathrm{Na}_{2} \mathrm{O}}}{M_{\mathrm{Na}_{2} \mathrm{O}}}
$$

where $N a_{T}=$ total $\mathrm{Na}$ content $(\mathrm{mol} / \mathrm{g}) ; f_{\mathrm{Na} 2 \mathrm{O}}=\mathrm{Na}_{2} \mathrm{O}$ mass fraction $(\mathrm{g} / \mathrm{g})$; and $M_{\mathrm{Na} 2 \mathrm{O}}=$ molecular weight of $\mathrm{Na}_{2} \mathrm{O}(\mathrm{g} / \mathrm{mol})$.

The total release of alkali is given by the rapid release of alkali from sulphate salt and progressive release of alkali during hydration. The release of $\mathrm{Na}^{+}$is calculated as follows:

$$
N a_{\text {released }}^{+}=f_{N a, \text { sulfate }} * N a_{T}+\left(1-f_{N a, \text { sulfate }}\right) * \alpha * N a_{T}
$$

where $\mathrm{Na}_{\text {released }}^{+}=$total release of $\mathrm{Na}^{+}(\mathrm{mol} / \mathrm{g}) ; f_{\mathrm{Na} \text {,sulfate }}=$ fraction of $\mathrm{Na}^{+}$in sulphate salt; and $\alpha=$ degree of hydration

According to ref. (Brouwers et al. 2003), the amount of alkali ions bound on $\mathrm{C}-\mathrm{S}-\mathrm{H}$ is proportional to the concentration present in the solution and the amount of formed C-S-H. Therefore,

$$
N a_{\text {released }}^{+} m_{O P C}=\left[N a^{+}\right] V_{w}+R d_{N a}\left[N a^{+}\right] m_{C-S-H}
$$

where $m_{O P C}=$ mass of OPC $(\mathrm{g}) ; V_{w}=$ volume of pore water $\left(\mathrm{cm}^{3}\right) ;\left[\mathrm{Na}^{+}\right]=\mathrm{Na}^{+}$concentration in pore solution $\left(\mathrm{mol} / \mathrm{cm}^{3}\right) ; R d_{N a}=$ distribution ratio of $\mathrm{Na}^{+}\left(R d_{N a}=0.39\right.$ $\left.\mathrm{cm}^{3} / \mathrm{g} ; R d_{K}=0.38 \mathrm{~cm}^{3} / \mathrm{g}\right)$; and $m_{C-S-H}=$ mass of formed C-S-H (g)

The fraction of alkalis in sulphate salt and the distri-

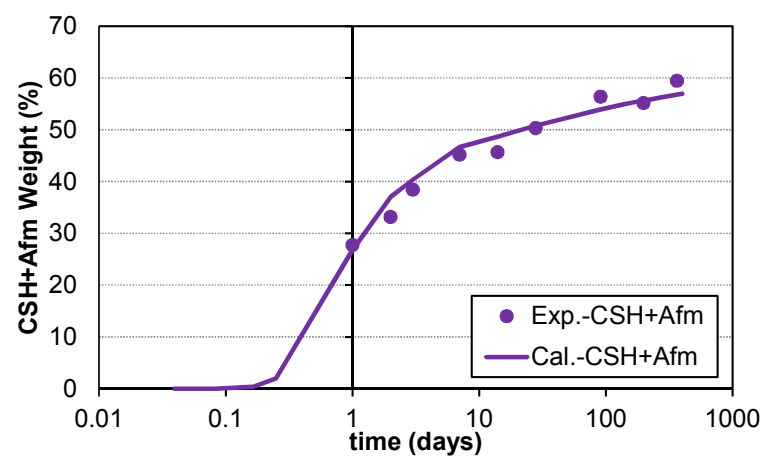

Fig. 9 Comparing the amount of amorphous hydrated products deduced by XRD/Rietveld analysis [Lothenbach et al. 2008] with calculated results as a function of hydration time. 
bution ratio of alkalis are constant values as reported in ref. (Brouwers et al. 2003). The above model is incorporated into the coupled model described in section 2 to determine the concentration of $\mathrm{Na}^{+}$and $\mathrm{K}^{+}$in the pore solution. At each time step, the concentration of $\mathrm{Na}^{+}$and $\mathrm{K}^{+}$are calculated from the degree of hydration, porosity or pore water, and amount of formed C-S-H (according to Eqs. (22-24)). The concentration of other ions in the pore solution, such as $\mathrm{Ca}^{2+}, \mathrm{SO}_{4}{ }^{2-}, \mathrm{Al}^{3+}, \mathrm{Si}$, and $\mathrm{OH}^{-}$, is calculated based on the thermodynamic equilibrium between cement hydrates and pore water. The concentration of $\mathrm{Na}^{+}$and $\mathrm{K}^{+}$in the pore solution as a result of hydration reaction changes the alkalinity of pore solution, thereby influences the dissolution/precipitation of phases.

The computed element concentrations in the pore solution of hydrated OPC are compared with the experimental data available in literature (Lothenbach et al. 2008). The same calculation procedure and input parameters as those described in section 3.1.1 are used to simulate the pore solution concentration. The calculated concentration of ions in the pore solution is then compared with the measured concentration, as shown in Fig. 10. The model predicts the presence of major elements such as $\mathrm{Na}, \mathrm{K}, \mathrm{OH}, \mathrm{Ca}, \mathrm{S}, \mathrm{Al}$, and $\mathrm{Si}$ in the pore solution. However, the presence of other elements, such as $\mathrm{Li}, \mathrm{Sr}$, $\mathrm{Ba}, \mathrm{Cr}$, and Mo, cannot be predicted using the current model even though they can be detected in the experiment. The simulated changes in pore solution concentration for major ions during hydration agree reasonably
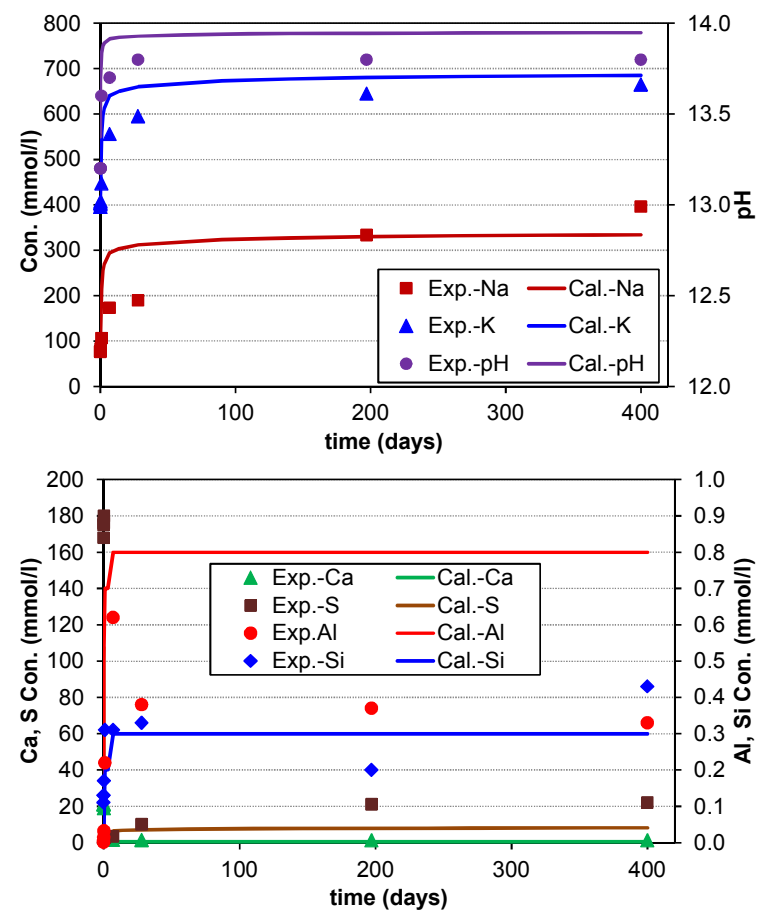

Fig. 10 Comparison of the calculated pore solution concentration during the hydration of OPC with the experimentally [Lothenbach et al. 2008] determined concentration. well with the experimental observation despite some discrepancies at early hydration time.

To further validate the prediction of the pore solution concentration, the calculated concentration of ions in the pore solution is compared with another experimental observation reported in literature for varying $\mathrm{W} / \mathrm{C}$ ratio (Larbi et al. 1990). To do this, the simulations were performed for OPC paste using the same cement composition and other experimental conditions adopted in ref. (Larbi et al. 1990). Figure 11 shows the predicted concentration of $\mathrm{Na}^{+}, \mathrm{K}^{+}, \mathrm{Ca}^{2+}$ and $\mathrm{pH}$ in the pore solution compared with the experimental data (Larbi et al. 1990) for different W/C ratios. Very good agreement was obtained between the experimental data and the simulation results after 7 days of hydration. However, the model predicts high concentration of ions at early hydration time. The model modification needs to be considered for

(A)

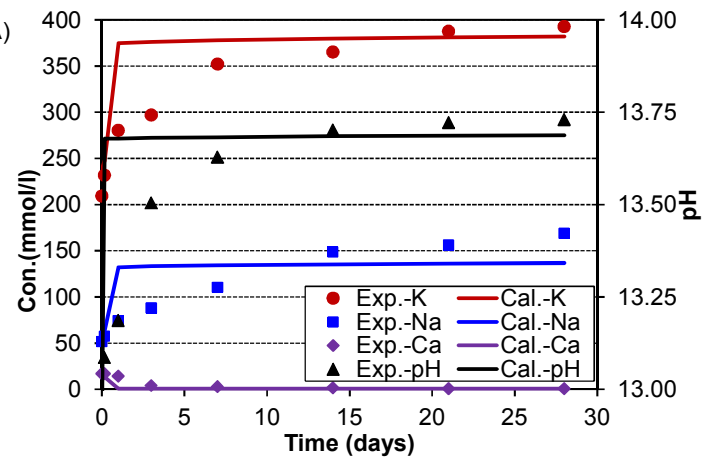

(B)

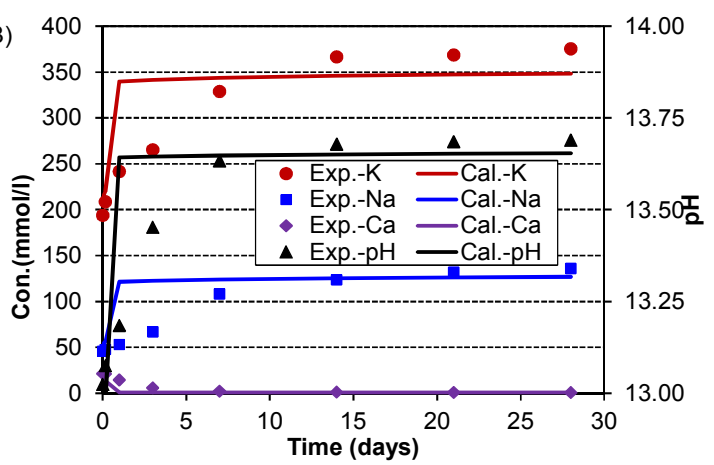

(C)

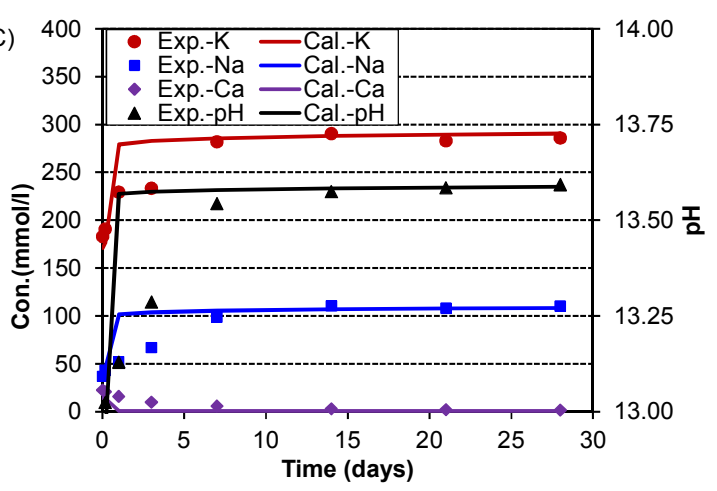

Fig. 11 Comparison between measured [Larbi et al. 1990] and calculated pore solution concentration of OPC paste with W/C of (A) 0.4 , (B) 0.45 , and (C) 0.56 during the first 28 days. 
accurate prediction at the early age as well. It is well known that the $\mathrm{W} / \mathrm{C}$ ratio influences not only the hydration of cement but also the porosity or pore size distribution. Therefore, pore solution composition is changed with $\mathrm{W} / \mathrm{C}$ due to changes in the amount of formed C-S$\mathrm{H}$, porosity, hydration degree, etc. (Fig. 11). The coupled model can successfully predict these changes as well.

\subsubsection{Total calcium profiles: Calcium leaching}

To validate the proposed model in terms of calcium leaching from cementitious materials, experimental data on a test specimen was collected from literature (Samson and Marchand 2007). Briefly, a calcium leaching experiment was conducted on a cement paste sample with $\mathrm{W} / \mathrm{C}$ of 0.6 . The paste was prepared using an OPC (Canadian CSA Type 10), and it was cured for 12 months at room temperature in a sealed condition. After the curing period, a $20 \mathrm{~mm}$ disk was prepared for the calcium leaching experiment. All the faces of the sample were sealed with silicon except for one circular face, and it was then immersed in $30 \mathrm{~L}$ of deionized water for 3 months. The external solution was renewed every week in order to maintain uniform conditions. After the exposure test, the sample was analysed using a microprobe to determine the calcium profile (Samson and Marchand 2007).

One-dimensional numerical analysis was performed to simulate the experiment. The necessary input parameters such as cement composition, mix proportion, and boundary condition were the same as those used in the experiment. As for multispecies transport, the main ions such as $\mathrm{Na}^{+}, \mathrm{K}^{+}, \mathrm{SO}_{4}{ }^{2-}, \mathrm{Ca}^{2+}, \mathrm{OH}^{-}, \mathrm{Al}^{3+}$, and $\mathrm{H}_{2} \mathrm{SiO}_{4}{ }^{2-}$ were considered. The concentration of these species is set to zero at the exposure surface $(x=0)$. Further, the initial $(t=0)$ concentration of ions in the sample is zero because they are calculated during the analysis. The spatial distribution of total calcium content was calculated as the sum of calcium in hydrated phases, unhydrated cement and pore solution, and it is then converted to gram per kilogram of dry material that is spatially calculated at the end of the simulation period. The comparison between the total calcium profiles as calculated from the proposed model and that determined experimentally is shown in Fig. 12. The figure also compares the results obtained in this study with those obtained from the STADIUM model (Samson and Marchand 2007). The proposed model correctly predicts the leaching of calcium ions from cement paste exposed to deionized water. The dissolution of portlandite and C-S$\mathrm{H}$ are responsible for the total content of calcium in the sample. The dissolution increases the porosity of the matrix; this, in turn, enhances further leaching of ions. This effect has been taken into account in the proposed model by coupling the transport equation (described in section 2.2) with the pore structure modification model (described in section 2.4). It should be noted that the simulation result was obtained without using any fitting

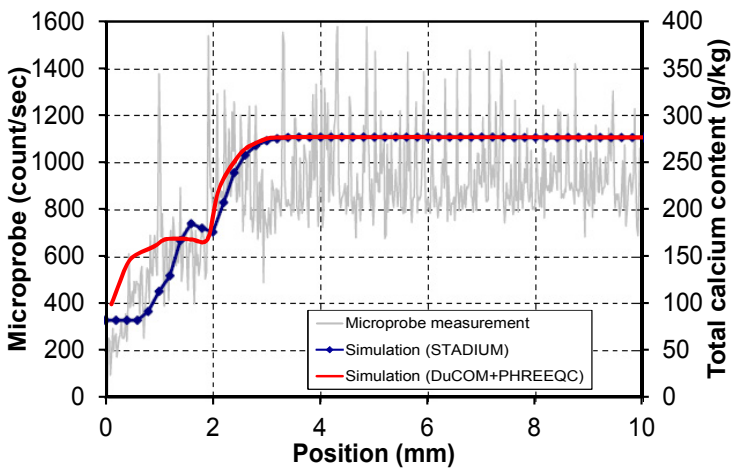

Fig. 12 Comparison of calculated total calcium profiles for the paste exposed to pure water for 3 months with experimental profiles [Samson and Marchand 2007]. Plain line refers to the results of this study while line with mark refers to the results of the STADIUM model [Samson and Marchand 2007].

parameter, and thus the proposed model very well reproduces the experimental profile.

\subsubsection{Total calcium and sulphate profiles: Ex- ternal sulphate attack}

The proposed model was tested against the external sulphate attack in cementitious materials. The model was used to reproduce the measured calcium and sulphur profiles in cement paste that was immersed in sodium sulphate solution. The profiles in cement paste immersed in $50 \mathrm{mmol} / \mathrm{l}$ sodium sulphate solution were taken from the results found in ref. (Samson and Marchand 2007). The experimental procedures to obtain the total calcium and sulphur profiles have already been described briefly in section 3.1.3. However, the exposure solution was $50 \mathrm{mmol} / \mathrm{l}$ sodium sulphate instead of deionized water, and the profiles were taken at three different exposure time (3, 6, and 12 months) intervals.

A similar analysis that has already been outlined in section 3.1.3 was performed in here, where the concentration of $\mathrm{Na}^{+}$and $\mathrm{SO}_{4}{ }^{2-}$ is set to $100 \mathrm{mmol} / \mathrm{l}$ and 50 $\mathrm{mmol} / \mathrm{l}$ respectively, whereas those of other species remain zero at the exposure surface $(x=0)$. A comparison of the total calcium profiles as calculated from the proposed model with measured values at the end of 3,6 , and 12 months for the paste exposed to sodium sulphate solution is shown in Fig. 13. The prediction results from the STADIUM model (Samson and Marchand 2007) are also presented in the graph. As previously explained, the leaching of calcium from portlandite and C-S-H is the dominant factor for the remaining total calcium in the solids. The results show strong leaching near the sample surface, and the degradation is much more pronounced in the case for paste interacting with sodium sulphate solution than that observed in deionized water. Furthermore, an inward movement of the degradation front can be observed with time. The simulation results show a small peak of calcium at around $1 \mathrm{~mm}$ from the exposure surface, and the peak is going inside with time. This is 

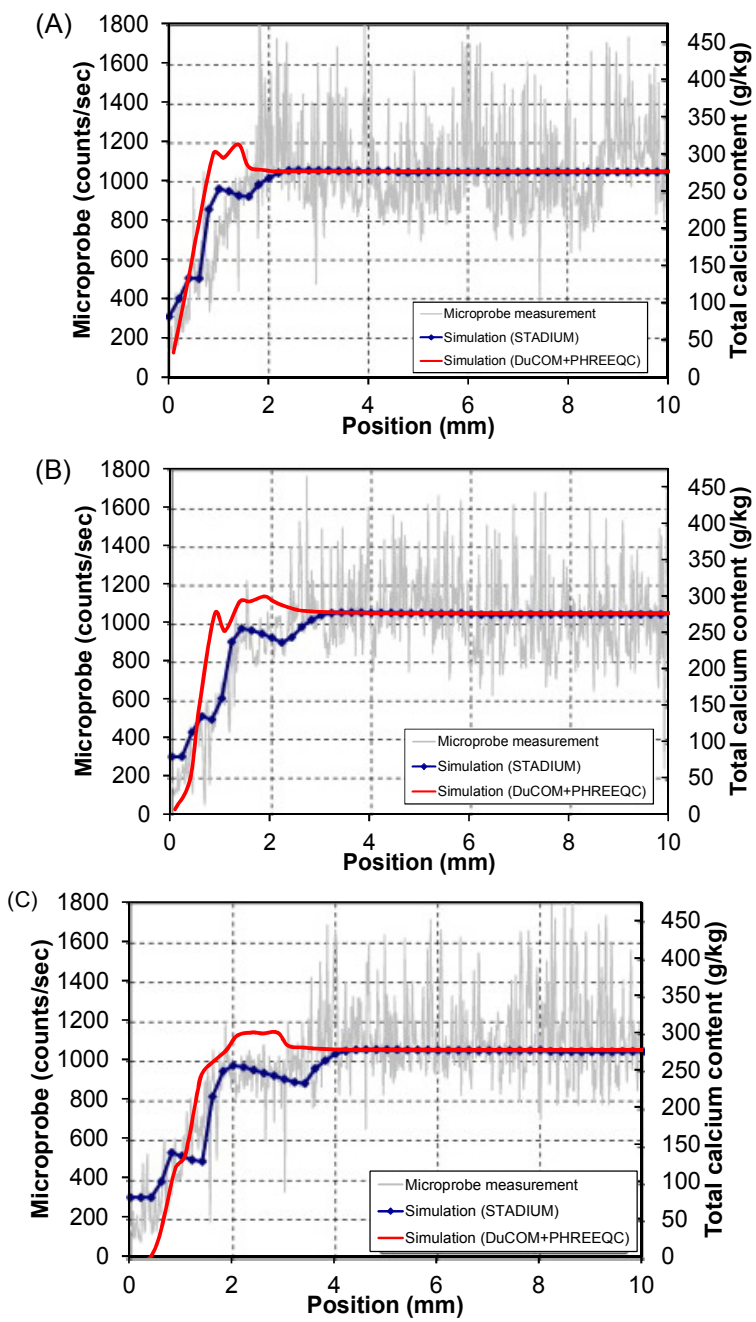

Fig. 13 Comparison between measured [Samson and Marchand 2007] and calculated total calcium profiles for the paste exposed to $50 \mathrm{mmol} / \mathrm{l} \mathrm{Na2SO} 4$ solution for a period of (A) 3 months, (B) 6 months, and (C) 12 months. Plain line refers to the results of this study while line with mark refers to the results of the STADIUM model [Samson and Marchand 2007].

associated with the precipitation of gypsum in the presence of diffused calcium and sulphate ions. The destabilization of portlandite and C-S-H produces calcium ions that can diffuse toward the exposure surface as well as inside the sample. The calculated concentration of calcium in the pore solution for the paste exposed to sodium sulphate solution for a period of 3 months is shown in Fig. 14. The figure explains the reason behind the peak of calcium inside the sample (as shown in Fig. 13).

The same analysis was carried out to determine the sulphur profiles at the end of end of 3, 6, and 12 months for the paste exposed to sodium sulphate solution. The simulated results compared with the experimental profiles are shown in Fig. 15 along with the numerical results of the STADIUM model (Samson and Marchand 2007). The total sulphur content is mainly contributed

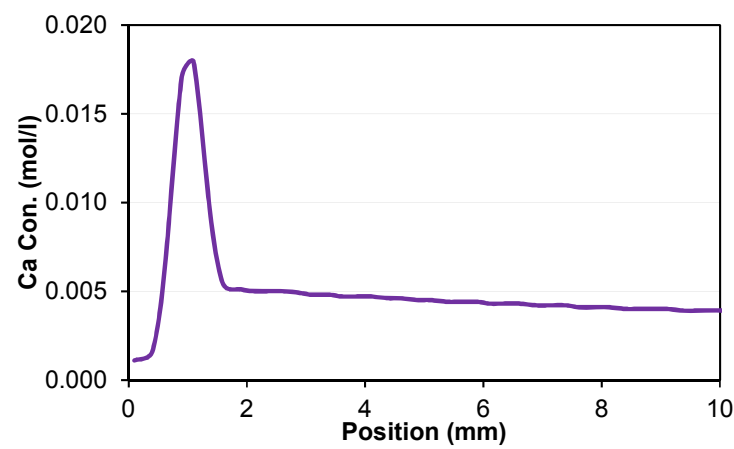

Fig. 14 Calculated calcium ion concentration in pore solution for the paste exposed to $50 \mathrm{mmol} / / \mathrm{Na}_{2} \mathrm{SO}_{4}$ solution for a period of 3 months.
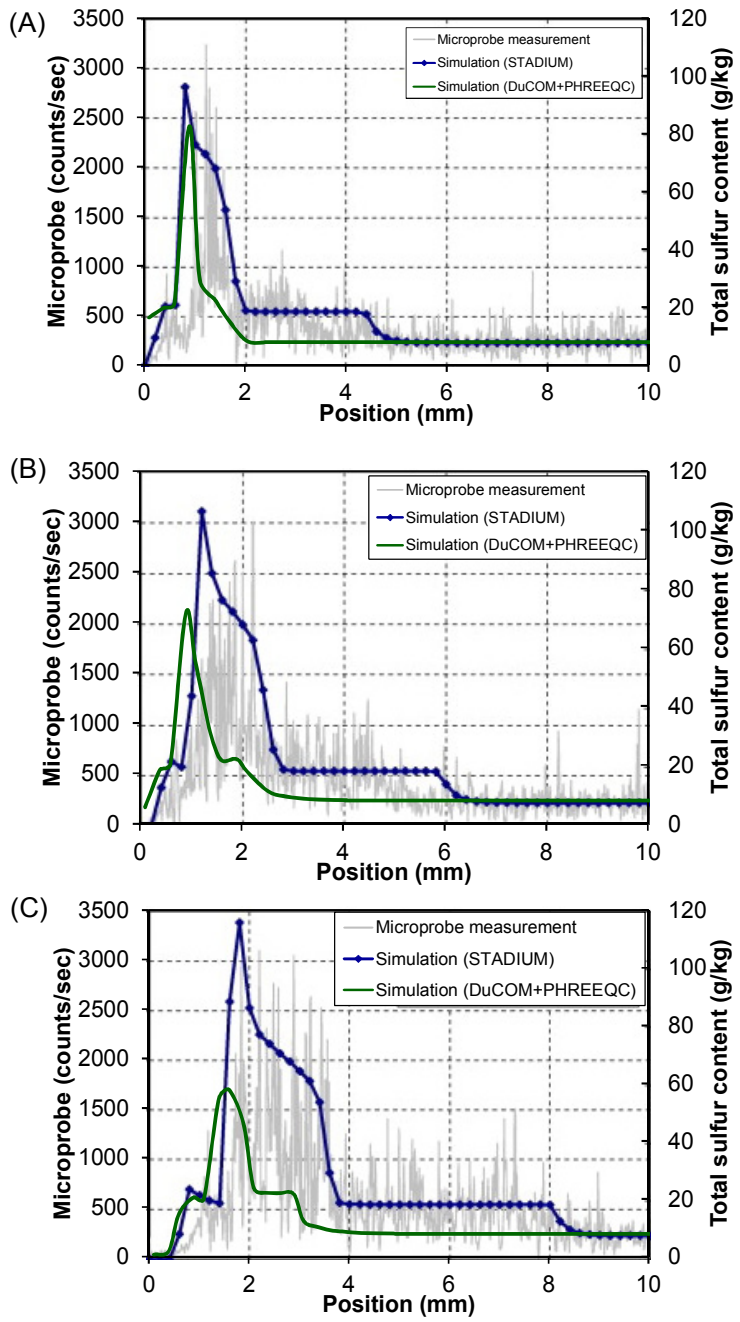

Fig. 15 Comparison between measured [Samson and Marchand 2007] and calculated total sulphur profiles for the paste exposed to $50 \mathrm{mmol} / \mathrm{l} \mathrm{Na} \mathrm{SO}_{4}$ solution for a period of (A) 3 months, (B) 6 months, and (C) 12 months. Plain line refers to the results of this study while line with mark refers to the results of the STADIUM model [Samson and Marchand 2007].

by the presence of sulphur in gypsum and ettringite. It is important to note that the proposed model considers the monosulphate and a part of the portlandite are converted 
to ettringite until all the aluminium in monosulphate is consumed to form ettringite. The increase in the total sulphur content above the initial sulphate in the paste corresponds to the formed ettringite layer as a result of sulphate ingress. The increment of ettringite layer over time can be observed both from the experimental and the modelling results (Fig. 15). The peaks in the sulphur profiles near the exposure surface occur owing to the precipitation of gypsum in the presence of diffused calcium and sulphate ions. As can be seen in the figure, the model results show the inward movement and widening of the peak with time. This corresponds to the dissolution of formed gypsum as a result of contact with the sodium sulphate solution. Overall, the proposed model reproduces the experimental results despite some discrepancies. The important features such as dissolution of portlandite, monosulphate and $\mathrm{C}-\mathrm{S}-\mathrm{H}$, and formation of ettringite and gypsum associated with the ingress of sulphate are consistent with other data reported in the literature (Lothenbach et al. 2010b; Samson and Marchand 2007; Sarkar et al. 2010). Thus, cementitious materials under sulphate attack can reasonably be simulated using the model developed in this study.

\subsection{Significance of DuCOM-PHREEQC coupling}

A series of simulations was performed to evaluate the importance of coupling the DuCOM and PHREEQC. The OPC concrete exposed to groundwater was considered for this case. The parameters needed to perform the calculations are tabulated in Table 1. In the simulation, one side of the concrete was considered to be in contact with groundwater and the other side was free. A onedimensional multispecies transport coupled with geochemical reactions was considered. The simulation was performed for fully saturated case where the degree of saturation at each node is explicitly set to one during the calculation. The chemical composition of groundwater adopted for the simulation is given in Table 2 . As described in section 3.1.1, the initial hydration products of OPC are dominated by C-S-H (with $\mathrm{CaO}: \mathrm{SiO}_{2}$ ratio of 1.6), portlandite, ettringite, monosulphate, and gypsum. In addition to these hydrates, other phases expected to form under these environments have also been taken into account in the model. The main ions in the pore solution and exposure solution such as $\mathrm{Na}^{+}, \mathrm{K}^{+}, \mathrm{Mg}^{2+}$, $\mathrm{SO}_{4}{ }^{2-}, \mathrm{Ca}^{2+}, \mathrm{OH}^{-}, \mathrm{Cl}^{-}, \mathrm{Al}^{3+}, \mathrm{H}_{2} \mathrm{SiO}_{4}{ }^{2-}$, and $\mathrm{HCO}_{3}{ }^{-}$were considered for ionic transport. It is assumed that the thermodynamic reaction between other species in groundwater and cement hydrates can be negligible.

Figure 16 shows the simulation results for distribution of phases in terms of volume percentage resulting from multispecies transport and thermodynamic reactions. It is important to note that the DuCOMPHREEQC system has strong coupling among various processes and mechanisms such as hydration, micropore structure development, multispecies transport, and chemical reactions. The simulation result for the case with complete coupling of DuCOM and PHREEQC is shown in Fig. 16(A). The figure also indicates the change in capillary porosity due to change in volume as a result of chemical reactions and continuous hydration. The progress of hydration increases the volume of hydration products mainly, C-S-H and portlandite, and consequently, decreasing capillary porosity (clearly seen in the specimen core). In this case, the capillary pore is nearly filled by the hydration products, but transport does not stop. As previously stated, the porosity in the governing equation (Eq. (1)) is the sum of the gel and the capillary, and the gel porosity exists as long as C-S$\mathrm{H}$ hydrates are present. Therefore, transport continues through the gel pore. Another important feature in the full suite of coupling is the additional hydration of unhydrated cement, a kind of self-curing system for low W/C (Maekawa et al. 2009; Nakarai et al. 2006). The dissolution of cement hydrates near the exposure surface provides more space for un-hydrated cement to react with the existing free water, thus producing more $\mathrm{C}-\mathrm{S}-\mathrm{H}$ and portlandite. It can be seen that the position of the formation of the additional C-S-H front matches with the reaction of un-hydrated cement near the exposed surface.

Table 1 Input parameters for simulation.

\begin{tabular}{|c|c|}
\hline Material & OPC concrete \\
\hline Mineralogical analyses of OPC (\%) By Bougue method \\
\hline -Alite & 56.70 \\
\hline -Belite & 17.81 \\
\hline -Aluminate & 9.66 \\
\hline -Ferrite & 8.42 \\
\hline -Gypsum & 4.00 \\
\hline \multicolumn{2}{|c|}{ Composition of alkalis (\%) } \\
\hline$-\mathrm{Na}_{2} \mathrm{O}$ & 0.21 \\
\hline$-\mathrm{K}_{2} \mathrm{O}$ & 0.82 \\
\hline $\mathrm{Characteristics} \mathrm{of} \mathrm{concrete} \mathrm{mixtures}^{-\mathrm{W} / \mathrm{C}}$ & 0.35 \\
\hline -Coarse aggregates $\left(\mathrm{kg} / \mathrm{m}^{3}\right)$ & 1035.0 \\
\hline -Fine aggregates $\left(\mathrm{kg} / \mathrm{m}^{3}\right)$ & 803.0 \\
\hline Specimen thickness & $10 \mathrm{~cm}$ \\
\hline Curing period and condition & 28 days water curing \\
\hline Exposure period & 50 years \\
\hline Temperature & $20{ }^{\circ} \mathrm{C}$ \\
\hline
\end{tabular}

Table 2 Ground water composition (JNC 2000).

\begin{tabular}{|c|c|}
\hline \multicolumn{2}{|c|}{ Chemical composition } \\
\hline $\mathrm{pH}$ & 8.5 \\
\hline $\mathrm{Eh}(\mathrm{mV})$ & -281 \\
\hline $\mathrm{E}$ Element concentration $(\mathrm{mol} / \mathrm{l})$ \\
\hline $\mathrm{Na}$ & $3.6^{*} 10^{-3}$ \\
\hline $\mathrm{K}$ & $6.2^{*} 10^{-5}$ \\
\hline $\mathrm{Ca}$ & $1.1 * 10^{-4}$ \\
\hline $\mathrm{Mg}$ & $5.0^{*} 10^{-5}$ \\
\hline $\mathrm{B}$ & $2.9^{*} 10^{-4}$ \\
\hline $\mathrm{P}$ & $2.9^{*} 10^{-6}$ \\
\hline $\mathrm{F}$ & $5.4^{*} 10^{-5}$ \\
\hline $\mathrm{Cl}$ & $1.5^{*} 10^{-5}$ \\
\hline $\mathrm{SO}_{4}$ & $1.1^{*} 10^{-4}$ \\
\hline $\mathrm{NO}_{3}$ & $2.3^{*} 10^{-5}$ \\
\hline $\mathrm{CO}_{3}$ & $3.5^{*} 10^{-3}$ \\
\hline $\mathrm{Si}$ & $3.4^{*} 10^{-4}$ \\
\hline
\end{tabular}



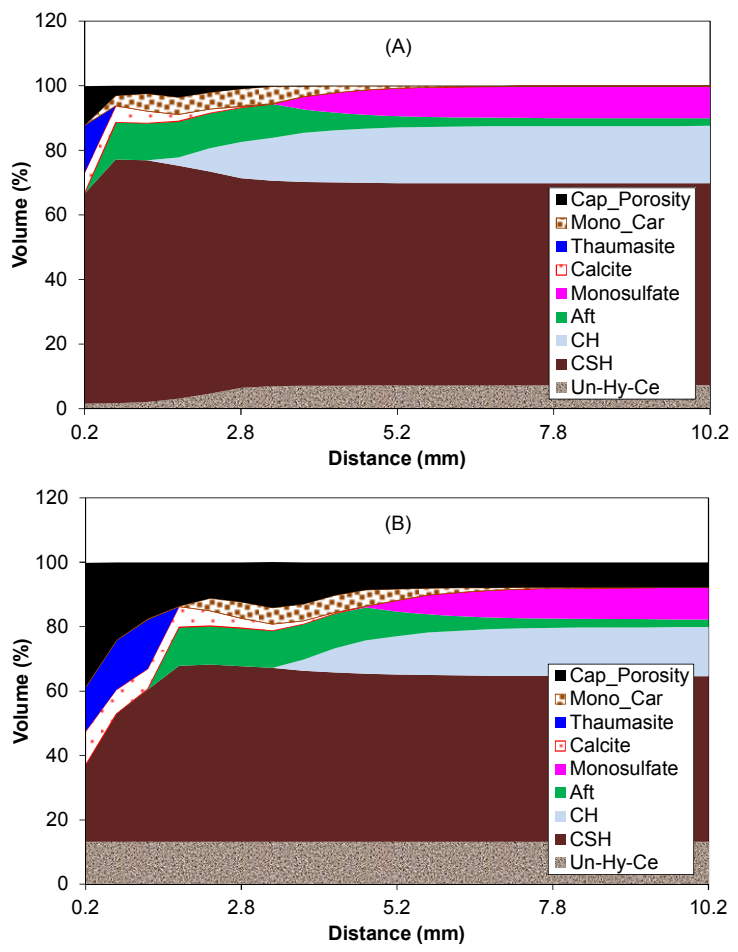

Fig. 16 Representation of the distribution of phases in OPC concrete with W/C of 0.35 that exposed to groundwater for 50 years: (A) Results from coupled DuCOMPHREEQC model, and (B) Results from a trial model which does not consider the progress and additional hydration of un-hydrated cement. Cap_porosity: Capillary porosity; Mono_Car: Monocarbonate; Aft: Ettringite; $\mathrm{CH}$ : Portlandite; CSH: C-S-H with $\mathrm{Ca} / \mathrm{Si}$ of 1.6; Un-HyCe: Un-hydrated cement.

In order to investigate the importance of the coupling hydration model with the reactive transport and micropore structure modification models, another simulation was performed where the progress of hydration and additional hydration from the dissolution of hydrates is neglected. The simulation result is shown in Fig. 16(B). The amount of hydrated products and porosity in the specimen core (after $8 \mathrm{~mm}$ from the exposed surface) is exactly the same as that in the initial condition before contact with groundwater (after 28 days of hydration). The simulation result shows that neglecting the coupling of both the progress and the additional hydration with reactive transport leads to more degradation. The extensive dissolution of portlandite and C-S-H near the exposed surface causes degradation, which is much more progress than that obtained from the complete coupling of DuCOM and PHREEQC. The progress of hydration and its effect on the pore structure and transport for low $\mathrm{W} / \mathrm{C}$ concrete is well known. These phenomena can be simulated only by a model that has strong coupling among the hydration of cement particles, micro-pore formation and/or modification, and reactive transport. The developed DuCOM-PHREEQC system fulfils this purpose, and thus it can serve as a valuable tool for the assessment of the long-term performance of cementitious materials in various environments.

\section{Concluding remarks}

A coupled physicochemical and geochemical model is developed for assessing cementitious materials in aggressive environments. A multi-scale model (Maekawa et al. 2009) developed by the Concrete Laboratory at the University of Tokyo is extended in this study by coupling an existing geochemical code PHREEQC (Parkhust and Appelo 1999; Charlton et al. 2011) to solve multispecies transport problems together with a comprehensive set of geochemical reactions. In contrast to existing models, the coupled model does not require physical or chemical properties of cementitious materials in advance as input parameters because these are calculated automatically in the model. The coupled model allows the prediction of the spatiotemporal variation of cement hydrate composition, pore water concentration, other hydration and pore structure properties, etc. The model was validated by comparing the simulation results with the experimental data available in the literature. The good agreement between the calculation and the experimental data indicates that the important features and processes have been included in the coupled model for the assessment of cementitious materials in aggressive environments. The full suite of coupling the DuCOM and PHREEQC is evaluated for concrete in groundwater environment as an example. Comparing the simulation results with and without progress and addition hydration of un-hydrated cement emphasized the importance of coupling the hydration model in the system.

\section{Acknowledgement}

The grant from the Japan Society for the Promotion of Science Funding Program for Next Generation WorldLeading Researchers (NEXT Program, Representative: Dr. T. Ishida) is gratefully acknowledged.

\section{References}

Appelo, C. A. J., \& Wersin, P., (2007). "Multicomponent diffusion modeling in clay systems with application to the diffusion of tritium, iodide, and sodium in opalinus clay." Environmental Science \& Technology, 41, 5002-5007.

Appelo, C. A. J. and Postma, D., (2009). "Geochemistry, groundwater and pollution." CRC Press Taylor \& Francis Group.

Blanc, P., Bourbon, X., Lassin, A. and Gaucher, E. C., (2010a). "Chemical model for cement-based materials: Temperature dependence of thermodynamic functions for nanocrystalline and crystalline C-S-H phases." Cement and Concrete Research, 40, 851-866.

Blanc, P., Bourbon, X., Lassin, A. and Gaucher, E. C., (2010b). "Chemical model for cement-based materials: Thermodynamic data assessment for phases other than C-S-H." Cement and Concrete Research, $40,1360-1374$. 
Brouwers, H. J. H and Eijk, R. J., (2003). "Alkali concentration of pore solution in hydrating OPC." Cement and Concrete Research, 33, 191-196.

Charlton, S. R. and Parkhurst, D. L., (2011). "Modules based on the geochemical model PHREEQC for use in scripting and programming languages." Computers \& Geosciences, 37, 1653-1663.

Elakneswaran, Y., Iwasa, A., Nawa, T., Sato. T. and Kurumisawa, K., (2010). Ion-cement hydration govern multi-ionic transport model for cementitious materials." Cement and Concrete Research, 40, 17561765.

Hosokawa, Y., Yamada, K., Johannesson B. and Nilsson, L.-O., (2011). Development of a multi-species mass transport model for concrete with account to thermodynamic phase equilibrium, Materials and Structures, 44, 1577-1592.

Ishida, T., Iqbal, P. O. and Anh, H. T. L., (2009). "Modeling of chloride diffusivity coupled with nonlinear binding capacity in sound and cracked concrete." Cement and Concrete Research, 39, 913923.

JNC, (2000). "H12: Project to establish the scientific and technical basis for HLW disposal in Japan." Japan Nuclear Cycle Development Institute.

Kari, O. P., Elakneswaran, Y., Nawa, T. and Puttonen, J., (2013). A model for a long-term diffusion of multispecies in concrete based on ion-cement-hydrate interaction." Journal of Materials Science, 12, 42434259.

Larbi, J. A., Fraay, A. L. A. and Bijen, J. M. J. M., (1990). "The chemistry of pore fluid of silica fumeblended cement systems." Cement and Concrete Research, 20, 506-516.

Lothenbach, B. and Winnefeld, F., (2006). "Thermodynamic modeling of the hydration of Portland cement." Cement and Concrete Research, 36, 209-226.
Lothenbach, B., Le Saout, G., Gallucci, E. and Scrivener, K., (2008). "Influence of limestone on the hydration of Portland cement." Cement and Concrete Research, $38,848-860$.

Lothenbach, B., (2010a). "Thermodynamic equilibrium calculations in cementitious systems." Materials and Structures, 43, 1413-1433.

Lothenbach, B., Bary, B., Le Bescop, P., Schmidt, T. and Leterrier, N., (2010b). "Sulfate ingress in Portland cement." Cement and Concrete Research, 40, 12111225 .

Maekawa, K., Ishida, T. and Kishi, T., (2009). "Multiscale modeling of structural concrete." Taylor \& Francis.

Marchand, J., Samson, E., Maltais, Y. and Beaudoin, J. J., (2002). "Theoretical analysis of the effect of weak sodium sulfate solutions on the durability of concrete." Cement \& Concrete Composites, 24, 17329.

Matschei, T., Lothenbach, B. and Glasser, F. P., (2007). "The AFm phase in Portland cement." Cement and Concrete Research, 37, 118-130.

Nakarai, K., Ishida, T. and Maekawa, K., (2006). "Modeling of calcium leaching from cement hydrates coupled with micro-pore formation." Journal of Advanced Concrete Technology, 4, 395-407.

Parkhust, D. L. and Appelo, C. A. J., (1999). "A computer program for speciation, batch - reaction, one - dimensional transport and inverse geochemical calculations." USGS report.

Samson, E. and Marchand, J., (2007). "Modelling the transport of ions in unsaturated cement-based materials." Computer \& Structures, 85, 1740-1756

Sarkar, S., Mahadevan, S., Meeussen, J. C. L., van der Sloot, H. and Kosson, D. S., (2010). "Numerical simulation of cementitious materials degradation under external sulphate attack." Cement \& Concrete Composites, 32, 241-252. 